\title{
Generalization of fixed point theorems in ordered metric spaces concerning generalized distance
}

\author{
Elham Graily ${ }^{1}$, Seiyed Mansour Vaezpour ${ }^{2}$, Reza Saadati ${ }^{{ }^{*}}$ and Yeol JE Cho ${ }^{3}$
}

\author{
* Correspondence: RSAADATI@EML. \\ CC \\ 'Department of Mathematics, \\ Science and Research Branch, \\ Islamic Azad University (lau), \\ Tehran, Iran \\ Full list of author information is \\ available at the end of the article
}

\author{
Abstract \\ In this article, we consider ordered metric spaces concerning generalized distance \\ and prove some fixed point theorems in these spaces. Our results generalize, \\ improve, and simplify the proof of the previous results given by some authors. \\ Mathematics Subject Classification (2000) \\ $47 \mathrm{H} 10,54 \mathrm{H} 25$
}

Keywords: Ordered metric space, Fixed point, Generalized distance

\section{Introduction and Preliminary}

Recently, Nieto and Rodriguez-Lopez [1,2], Ran and Reurins [3], Petrusel and Rus [4] presented some new results in partially ordered metric spaces. Their main idea was to combine the ideas of iterative technique in the contractive mapping with these in monotone technique.

Recently, Kada et al. [5,6] in 1996 introduced the concept of $w$-distance in a metric space and prove some fixed point theorems. For the study of fixed point theorem concerning generalized distance followed in other articles, see [5,7-15].

The aim of this article is to use the concept of $w$-distance to generalize the fixed point theorems in partially ordered metric spaces. Our results not only generalize some fixed point theorems, but also improve and simplify the previous results.

In the sequel, we state some definitions and a lemma which we will use in our main results.

Definition 1.1. ([5,8,10]) Let $(X, d)$ be a metric space. Then, a function $p: X \times X \rightarrow$ $[0, \infty)$ is called a $w$-distance on $\mathrm{X}$ if the following conditions are satisfied:
(a) $p(x, z) \leq p(x, y)+p(y, z)$ for any $x, y, z \in X$;
(b) for any $x \in X, p(x,):. X \rightarrow[0, \infty)$ is lower semi-continuous;
(c) for any $\varepsilon>0$, there exists $\delta>0$ such that $p(x, z) \leq \delta$ and $p(z, y) \leq \delta$ imply $d(x, y)$ $\leq \varepsilon$.

We know that a real-valued function $f$ defined in a metric space $X$ is said to be lower semi-continuous at a point $x_{0} \in X$ if either $\liminf _{x_{n} \rightarrow x_{0}} f\left(x_{n}\right)=\infty$ or $f\left(x_{0}\right) \leq \liminf _{x_{n} \rightarrow x_{0}} f\left(x_{n}\right)$, whenever $x_{n} \in X$ for each $n \in \mathbf{N}$ and $x_{n} \rightarrow x_{0}$.

Lemma 1.2. ([5,7]) Let $(X, d)$ be a metric space and $p$ be a $w$-distance on $X$. Let $\left\{x_{n}\right\}$, $\left\{y_{n}\right\}$ be sequences in $X,\left\{\alpha_{n}\right\},\left\{\beta_{n}\right\}$ be sequences in $[0, \infty)$ converging to zero and let $x, y$,

(c) 2011 Graily et al; licensee Springer. This is an Open Access article distributed under the terms of the Creative Commons Attribution License (http://creativecommons.org/licenses/by/2.0), which permits unrestricted use, distribution, and reproduction in any medium, provided the original work is properly cited. 
$z \in X$. Then, the following conditions hold:

(1) If $p\left(x_{n}, y\right) \leq \alpha_{n}$ and $p\left(x_{n}, z\right) \leq \beta_{n}$ for any $n \in \mathbf{N}$, then $y=z$. In particular, if $p(x$. $y)=0$ and $p(x, z)=0$, then $y=z$;

(2) If $p\left(x_{n}, y_{n}\right) \leq \alpha_{n}$ and $p\left(x_{n}, z\right) \leq \beta_{n}$ for any $n \in \mathbf{N}$, then $d\left(y_{n}, z\right) \rightarrow 0$;

(3) If $p\left(x_{n}, x_{m}\right) \leq \alpha_{n}$ for any $n, m \in \mathbf{N}$ with $m>n$, then $\left\{x_{n}\right\}$ is a Cauchy sequence;

(4) If $p\left(y, x_{n}\right) \leq \alpha_{n}$ for any $n \in \mathbf{N}$, then $\left\{x_{n}\right\}$ is a Cauchy sequence.

Let $f: X \rightarrow X$ be an operator:

(1) $I(f)$ is the set of all nonempty invariant subsets of $f$, i.e., $I(f)=\{Y \subset X: f(Y) \subset Y$ \} and $F_{f}=\{x \in X: x=f(x)\}$.

(2) The operator $f$ is called Picard operator (briefly, PO) if there exists $x^{*} \in X$ such that $F_{f}=\left\{x^{* *}\right\}$ and, for all $x \in X,\left\{f^{n}(x)\right\}$ converges to $x^{*}$.

(3) The operator $f$ is called orbitally $U$-continuous for any $U \subset X \times X$ if the following condition holds:

For any $x \in X, f^{n_{i}}(x) \rightarrow a \in X$ as $i \rightarrow \infty$ and $\left(f^{n_{i}}(x), a\right) \in U$ for any $i \in \mathbf{N}$ imply that $f^{n_{i}+1}(x) \rightarrow f(a)$ as $i \rightarrow \infty$.

(4) Let $(X, \leq)$ be a partially ordered set. Then,

$$
X_{\leq}=\{(x, y) \in X \times X: x \leq y \text { or } y \leq x\}
$$

and $[x, y]_{\leq}=\{z \in X: x \leq z \leq y\}$, where $x, y \in X$ and $x \leq y$.

(5) If $g: Y \rightarrow Y$ is an operator, then the Cartesian product of $f$ and $g$ is the mapping $f \times g: X \times Y \rightarrow X \times Y$ defined by $(f \times g)(x, y)=(f(x), g(y))$ for all $(x, y) \in X \times$ $Y$.

(6) $\phi: R_{+} \rightarrow R_{+}$is said to be a comparison function if it is increasing and $\phi^{n}(t) \rightarrow 0$ as $n \rightarrow \infty$. As a consequence, we also have $\phi(t)<t$ for any $t>0, \phi(0)=0$, and $\phi$ is right continuous at 0 .

\section{Main Results}

Now, we give the main results of this article.

Theorem 2.1. Let $(X, d, \leq)$ be an ordered metric space and $f: X \rightarrow X$ be an operator. Let $p$ be a w-distance on $(X, d)$ and suppose that

(a) $X_{\leq} \in I(f \times f)$;

(b) there exists $x_{0} \in X$ such that $\left(x_{0}, f\left(x_{0}\right)\right) \in X_{\leq}$;

(c) $\left(c_{1}\right) f$ is orbitally continuous or

$\left(c_{2}\right) f$ is orbitally $X_{\leq}$-continuous and there exists a subsequence $\left\{f^{n_{k}}\left(x_{0}\right)\right\}$ of $\left\{f^{n}\left(x_{0}\right)\right\}$ such that $\left(f^{n_{k}}\left(x_{0}\right), x^{*}\right) \in X_{\leq}$for any $k \in \mathbf{N}$;

(d) there exists a comparison function $\phi: \boldsymbol{R}_{+} \rightarrow \boldsymbol{R}_{+}$such that

$$
p(f(x), f(y)) \leq \varphi\left(M_{x y}\right)
$$


for all $(x, y) \in X_{\leq}$, where

$$
M_{x y}=\max \left\{p(x, y), p(x, f(x)), p(y, f(y)), \frac{1}{2}(p(x, f(y))+p(y, f(x)))\right\} ;
$$

(e) the metric $d$ is complete.

Then $F_{f} \neq \varnothing$.

Proof. If $f\left(x_{0}\right)=x_{0}$, then the proof is completed. Let $x_{0} \in X$ be such that $\left(x_{0}, f\left(x_{0}\right)\right) \in$ $X_{\leq}$. By (a), since $(f \times f)\left(X_{\leq}\right) \subset X_{\leq}$, we have $(f \times f)\left(x_{0}, f\left(x_{o}\right)\right) \in X_{\leq}$and so $\left(f\left(x_{0}\right), f^{2}\left(x_{o}\right)\right) \in$ $X_{\leq}$.

Continuing this process, we obtain

$$
\left(f^{n}\left(x_{0}\right), f^{n+1}\left(x_{0}\right)\right) \in X_{\leq}
$$

for any $n \in \mathbf{N}$.

Now, we show that

$$
p\left(f^{n}\left(x_{0}\right), f^{n+1}\left(x_{0}\right)\right) \leq \varphi\left(p\left(f^{n-1}\left(x_{0}\right), f^{n}\left(x_{0}\right)\right)\right)
$$

for any $n \in \mathbf{N}$. Let $p_{0}=p\left(x_{0}, f\left(x_{0}\right)\right)$ and $p_{n}=p\left(f^{n}\left(x_{0}\right), f^{n+1}\left(x_{0}\right)\right)$ for any $n \in \mathbf{N}$. Then we have

$$
\begin{aligned}
p_{n} & \leq \varphi\left(\max \left\{p_{n-1}, p_{n}, p_{n-1}, \frac{1}{2}\left(p\left(f^{n-1}\left(x_{0}\right), f^{n}\left(x_{0}\right)\right)+p\left(f^{n}\left(x_{0}\right), f^{n+1}\left(x_{0}\right)\right)\right)\right\}\right) \\
& \leq \varphi\left(\max \left\{p_{n-1}, p_{n}, \frac{1}{2}\left(p_{n-1}+p_{n}\right)\right\}\right) \\
& \leq \varphi\left(\max \left\{p_{n-1}, p_{n}\right\}\right)
\end{aligned}
$$

for any $n \in \mathbf{N}$. If $\max \left\{p_{n-1}, p_{n}\right\}=p_{n-1}$, then (3.1) follows. Otherwise, $\max \left\{p_{n-1}, p_{n}\right\}=$ $p_{n}$ Then, by (3.2), we have $p_{n} \leq \phi\left(p_{n}\right) \leq p_{n}$ and so $p_{n}=0$ and (3.1) follows. By induction, we obtain

$$
p\left(f^{n}\left(x_{0}\right), f^{n+1}\left(x_{0}\right)\right) \leq \varphi^{n}\left(p\left(x_{0}, f\left(x_{0}\right)\right)\right)
$$

or, equivalently,

$$
p_{n} \leq \varphi^{n}\left(p_{0}\right)
$$

for any $n \in \mathbf{N}$, Now, we have

$$
p\left(f^{n}\left(x_{0}\right), f^{n+2}\left(x_{0}\right)\right) \leq p_{n}+p_{n+1} \leq \varphi^{n}\left(p_{0}\right)+\varphi^{n+1}\left(p_{0}\right) \rightarrow 0
$$

as $n \rightarrow \infty$.

Similarly, we have

$$
\begin{aligned}
p\left(f^{n}\left(x_{0}\right), f^{n+3}\left(x_{0}\right)\right) & \leq p\left(f^{n}\left(x_{0}\right), f^{n+2}\left(x_{0}\right)\right)+p_{n+2} \\
& \leq p\left(f^{n}\left(x_{0}\right), f^{n+2}\left(x_{0}\right)\right)+\varphi^{p+2}\left(p_{0}\right) \rightarrow 0
\end{aligned}
$$

as $n \rightarrow \infty$ and so, by induction, we obtain

$$
p\left(f^{n}\left(x_{0}\right), f^{n+k}\left(x_{0}\right)\right) \rightarrow 0
$$


as $n \rightarrow \infty$ for any $k>0$. Therefore, $\left\{f^{n}\left(x_{0}\right)\right\}$ is a Cauchy sequence in $X$. Since $X$ is complete, there exists $x^{*} \in X$ such that $f^{n}\left(x_{0}\right) \rightarrow x^{*}$ as $n \rightarrow \infty$.

Now, we show that $x^{*}$ is a fixed point. If $\left(c_{1}\right)$ holds, then $f^{n+1}\left(x_{0}\right) \rightarrow f\left(x^{*}\right)$ and, by lower semi-continuity of $p\left(f^{n}\left(x_{0}\right), \cdot\right)$, we have

$$
\begin{aligned}
& p\left(f^{n}\left(x_{0}\right), x^{*}\right) \leq \liminf _{m \rightarrow \infty} p\left(f^{n}\left(x_{0}\right), f^{m}\left(x_{0}\right)\right)=\alpha_{n}, \\
& p\left(f^{n}\left(x_{0}\right), f\left(x^{*}\right)\right) \leq \liminf _{m \rightarrow \infty} p\left(f^{n}\left(x_{0}\right), f^{m+1}\left(x_{0}\right)\right)=\beta n
\end{aligned}
$$

and $\alpha_{n}, \beta_{n} \rightarrow 0$ as $n \rightarrow \infty$. Thus, by (3.3) and Lemma 1.2, we conclude that $f\left(x^{*}\right)=$ $x^{*}$.

Now, suppose that $\left(c_{2}\right)$ holds. Since $\left\{f^{n_{k}}\left(x_{0}\right)\right\}$ converges to $x^{*}$ and $f$ is $X_{\leq}$-orbitally continuous, it follows that $f^{n_{k}+1}\left(x_{0}\right)$ converges to $f\left(x^{*}\right)$. Similarly, by lower semi-continuity of $p\left(f^{n}\left(x_{0}\right), \cdot\right)$, we conclude that $f\left(x^{*}\right)=x^{*}$. This completes the proof.

Corollary 2.2. Let $(X, d, \leq)$ be an ordered metric space and $f: X \rightarrow X$ be an operator. Let $p$ be a $w$-distance on $(X, d)$ and suppose that

(a) $X_{\leq} \in I(f \times f)$;

(b) there exists $x_{0} \in X$ such that $\left(x_{0}, f\left(x_{0}\right)\right) \in X_{\leq}$;

(c) $\left.\left(c_{1}\right)\right) f$ is orbitally continuous or

$\left(c_{2}\right) f$ is orbitally $X_{\leq}$-continuous and there exists a subsequence $\left\{f^{n_{k}}\left(x_{0}\right)\right\}$ of $\left\{f^{n}\right.$ $\left.\left(x_{0}\right)\right\}$ such that $\left(f^{n_{k}}\left(x_{0}\right), x^{*}\right) \in X_{\leq}$for any $k \in \mathbf{N}$;

(d) and there is a comparison function $\phi: \boldsymbol{R}_{+} \rightarrow \boldsymbol{R}_{+}$such that

$$
p(f(x), f(y)) \leq \varphi\left(M_{x y}\right)
$$

for any $(x, y) \in X_{\leq}$, where

$$
M_{x y}=\max \left\{p(x, y), p(x, f(x)), p(y, f(y)), \frac{1}{2}(p(x, f(y))+p(y, f(x)))\right\} ;
$$

(e) the metric $d$ is complete;

(f) if $(x, y) \in X_{\leq}$and $(y, z) \in X_{\leq}$.vskip $1 \mathrm{~mm}$

Then, $F_{f} \neq \varnothing$.

Theorem 2.3. Let $(X, d, \leq)$ be an ordered metric space and $f: X \rightarrow X$ be an operator. Let $p$ be a $w$-distance on $(X, d)$ and suppose that

(a) $X_{\leq} \in I(f \times f)$;

(b) There exists $x_{0} \in X$ such that $\left(x_{0}, f\left(x_{0}\right)\right) \in X_{\leq}$;

(c) $\left(c_{1}\right) f$ is orbitally continuous or

$\left(c_{2}\right) f$ is orbitally $X_{\leq}$-continuous and there exists a subsequence $\left\{f^{n_{k}}\left(x_{0}\right)\right\}_{o f}\left\{f^{n}\right.$ $\left.\left(x_{0}\right)\right\}$ such that $\left(f^{n_{k}}\left(x_{0}\right), x^{*}\right) \in X_{\leq}$for any $k \in \mathbf{N}$;

(d) there is a comparison function $\phi: \boldsymbol{R}_{+} \rightarrow \boldsymbol{R}_{+}$such that

$$
p(f(x), f(y)) \leq \varphi\left(M_{x y}\right)
$$


for any $(x, y) \in X_{\leq}$, where

$$
M_{x y}=\max \left\{p(x, y), p(x, f(x)), p(y, f(y)), \frac{1}{2}(p(x, f(y))+p(y, f(x)))\right\} ;
$$

(e) the metric $d$ is complete;

(f) if $x, y \in X$ with $(x, y) \notin X_{\leq}$, then there exists $c(x, y) \in X$ such that $(x, c(x, y)) \in$ $X_{\leq}$and $(y, c(x, y)) \in X_{\leq}$.

Then, $f$ is PO.

Proof. According to Theorem 2.1, there exists $x^{*} \in X$ such that $f\left(x^{*}\right)=x^{*}$. Take $x \in$ $X$.

If $\left(x, x_{0}\right) \in X_{\leq}$, then $\left(f^{n}(x), f^{n}(x 0)\right) \in X_{\leq}$and so

$$
p\left(f^{n}\left(x_{0}\right), f^{n}(x)\right) \leq \varphi^{n}\left(p\left(x_{0}, x\right)\right), \quad p\left(f^{n}\left(x_{0}\right), x^{*}\right) \leq \varphi^{n}\left(p\left(x_{0}, x^{*}\right)\right)
$$

for any $n \in \mathbf{N}$. Thus, by Lemma $1.2, f^{n}(x) \rightarrow x^{*}$ as $n \rightarrow \infty$.

If $\left(x, x_{0}\right) \notin X_{\leq}$, then there exists $z \in X$ such that $(x, z) \in X_{\leq}$and $\left(x_{0}, z\right) \in X_{\leq}$and so

$$
p\left(f^{n}\left(x_{0}\right), x^{*}\right) \leq \varphi^{n}\left(p\left(x_{0}, x^{*}\right)\right), \quad p\left(f^{n}\left(x_{0}\right), f^{n}(z)\right) \leq \varphi^{n}\left(p\left(x_{0}, z\right)\right)
$$

for any $n \in N$. Thus, by Lemma 1.2, we have $f^{n}(z) \rightarrow x^{*}$ as $n \rightarrow \infty$. Also, since $(x, z)$ $\in X_{\leq}$, we have $f^{n}(z) \rightarrow x^{*}$ as $n \rightarrow \infty$. Consequently, $f^{n}(x) \rightarrow x^{*}$ as $n \rightarrow \infty$.

Now, if there exist $y \in X$ such that $f(y)=y$, then

$$
p\left(f^{n}(\gamma), x^{*}\right) \leq \varphi^{n}\left(p\left(y, x^{*}\right)\right), \quad p\left(f^{n}(\gamma), \gamma\right) \leq \varphi^{n}(p(y, \gamma))
$$

and so, by Lemma 2.1, $y=x^{*}$, i.e., $F_{f}=\left\{x^{*}\right\}$. This completes the proof. $\square$

Corollary 2.4. Let $(X, d, \leq)$ be an ordered metric space and $f: X \rightarrow X$ be an operator. Let $p$ be a w-distance on $(X, d)$ and suppose that

(a) if $x, y \in X$ with $(x, y) X_{\leq}$there exists $c(x, y) \in X$ such that $(x, c(x, y)) \in X_{\leq}$and $(y, c(x, y)) \in X_{\leq}$;

(b) $X_{\leq} \in I(f \times f)$;

(c) There exists $x_{0} \in X$ such that $\left(x_{0}, f\left(x_{0}\right)\right) \in X_{\leq}$;

(d) $\left(d_{1}\right) f$ is orbitally continuous or $\left(d_{2}\right) f$ is orbitally $X_{\leq}$-continuous and there exists a subsequence $\left\{f^{n_{k}}\left(x_{0}\right)\right\}$ of $\left\{f^{n}\right.$ $\left.\left(x_{0}\right)\right\}$ such that $\left(f^{n_{k}}\left(x_{0}\right), x^{*}\right) \in X_{\leq}$for any $k \in \mathbf{N}$;

(e) there is a comparison function $\phi: \boldsymbol{R}_{+} \rightarrow \boldsymbol{R}_{+}$such that

$$
p(f(x), f(y)) \leq \varphi\left(M_{x y}\right)
$$

for any $(x, y) \in X_{\leq}$, where

$$
M_{x y}=\max \left\{p(x, y), p(x, f(x)), p(y, f(y)), \frac{1}{2}(p(x, f(y))+p(y, f(x)))\right\} ;
$$

(f) the metric $d$ is complete, 
Then, $f$ is $P O$.

Corollary 2.5. Let $(X, d, \leq)$ be an ordered metric space and $f: X \rightarrow X$ be an operator. Let $p$ be a w-distance on $(X, d)$ and suppose that

(a) if $x, y\left\lfloor X\right.$ with $(x, y) X_{\leq}$, then there exists $c(x, y) \in X$ such that $(x, c(x, y)) \in X_{\leq}$ and $(y, c(x, y)) \in X_{\leq}$;

(b) if $(x, y) \in X_{\leq}$and $(y, z) \in X_{\leq}$, then $(x, z) \in X_{\leq}$;

(c) $f$ is orbitally continuous (iv) there is a comparison function $\phi: \boldsymbol{R}_{+} \rightarrow \boldsymbol{R}_{+}$such that

$$
p(f(x), f(y)) \leq \varphi\left(M_{x y}\right)
$$

for any $(x, y) \in X_{\leq}$, where

$$
M_{x y}=\max \left\{p(x, y), p(x, f(x)), p(y, f(y)), \frac{1}{2}(p(x, f(y))+p(y, f(x)))\right\} ;
$$

(d) the metric $d$ is complete,

Then, $f$ is $P O$.

Corollary 2.6. Let $(X, d, \leq)$ be an ordered metric space and $f: X \rightarrow X$ be an operator. Let $p$ be a w-distance on $(X, d)$ and suppose that

(a) if $x, y \in X$ with $(x, y) X_{\leq}$, then there exists $c(x, y) \in X$ such that $(x, c(x, y)) \in X_{\leq}$ and $(y, c(x, y)) \in X_{\leq}$

(b) $X_{\leq} \in I(f \times f)$;

(c) there exists $x_{0} \in X$ such that $\left(x_{0}, f\left(x_{0}\right)\right) \in X_{\leq}$;

(d) if $(x, y) \in X_{\leq}$and $(y, z) \in X_{\leq}$, then $(x, z) \in X_{\leq}$;

(e) $\left(e_{1}\right) f$ is orbitally continuous or

$\left(e_{2}\right) f$ is orbitally $X_{\leq}$-continuous and there exists a subsequence $\left\{f^{n_{k}}\left(x_{0}\right)\right\}$ of $\left\{f^{n}\right.$ $\left.\left(x_{0}\right)\right\}$ such that $\left(f^{n_{k}}\left(x_{0}\right), x^{*}\right) \in X_{\leq}$for any $k \in \mathbf{N}$;

(f) there is a comparison function $\phi: \boldsymbol{R}_{+} \rightarrow \boldsymbol{R}_{+}$such that

$$
p(f(x), f(y)) \leq \varphi\left(M_{x y}\right)
$$

for any $(x, y) \in X_{\leq}$, where

$$
M_{x y}=\max \left\{p(x, y), p(x, f(x)), p(y, f(y)), \frac{1}{2}(p(x, f(y))+p(y, f(x)))\right\} ;
$$

(g) the metric $d$ is complete,

Then, $f$ is $P O$.

Corollary 2.7. Let $(X, d, \leq)$ be an ordered metric space and $f: X \rightarrow X$ be an operator. Let $p$ be a w-distance on $(X, d)$ and suppose that 
(a) if $x, y \in X$ with $(x, y) X_{\leq}$, then there exists $c(x, y) \in X$ such that $(x, c(x, y)) \in X_{\leq}$ and $(y, c(x, y)) \in X_{\leq}$;

(b) $f$ is increasing or decreasing;

(c) there exists $x_{0} \in X$ such that $\left(x_{0}, f\left(x_{0}\right)\right) \in X_{\leq}$;

(d) $\left(d_{1}\right) f$ is orbitally continuous or

$\left(d_{2}\right) f$ is orbitally $X_{\leq}$-continuous and there exists a subsequence $\left\{f^{n_{k}}\left(x_{0}\right)\right\}$ of $\left\{f^{n}\right.$ $\left.\left(x_{0}\right)\right\}$ such that $\left(f^{n_{k}}\left(x_{0}\right), x^{*}\right) \in X_{\leq}$for any $k \in \mathbf{N}$;

(e) there is a comparison function $\phi: \boldsymbol{R}_{+} \rightarrow \boldsymbol{R}_{+}$such that

$$
p(f(x), f(y)) \leq \varphi\left(M_{x y}\right)
$$

for any $(x, y) \in X_{\leq}$, where

$$
M_{x y}=\max \left\{p(x, y), p(x, f(x)), p(y, f(y)), \frac{1}{2}(p(x, f(y))+p(y, f(x)))\right\} ;
$$

(f) the metric $d$ is complete,

\section{Then, $f$ is PO.}

\section{Acknowledgements}

The authors would like to thank the referees and area editor Professor Simeon Reich for giving useful suggestions and comments for the improvement of this article. Y. J. Cho was supported by the Korea Research Foundation Grant funded by the Korean Government (KRF-2008-313-C00050).

\section{Author details}

${ }^{1}$ Department of Mathematics, Science and Research Branch, Islamic Azad University (lau), Tehran, Iran ${ }^{2}$ Department of Mathematics and Computer Science, Amirkabir University of Technology, 424 Hafez Avenue, Tehran 15914, Iran

${ }^{3}$ Department of Mathematics Education and the Rins, Gyeongsang National University, Chinju 660-701, Korea

\section{Authors' contributions}

All authors carried out the proof. All authors conceived of the study, and participated in its design and coordination. All authors read and approved the final manuscript.

\section{Competing interests}

The authors declare that they have no competing interests.

Received: 14 March 2011 Accepted: 11 August 2011 Published: 11 August 2011

\section{References}

1. Nieto, JJ, Rodriguez-Lopez, R: Contractive mapping theorems in partially ordered sets and applications to ordinary differential equations. Order. 22, 223-239 (2005). doi:10.1007/s11083-005-9018-5

2. Nieto, JJ, Rodriguez-Lopez, R: Existence and uniqueness of fixed point in partially ordered sets and applications to ordinary differential equations. Acta Math Sin Eng. 23, 2205-2212 (2007). doi:10.1007/s10114-005-0769-0

3. Ran, AC, Breurings, MC: A fixed point theorems in partially ordered sets and some applications to metric equations. Proc Am Math Soc. 132, 1435-1443 (2004). doi:10.1090/50002-9939-03-07220-4

4. Petrusel, A, Rus, IA: Fixed point theorems in ordered L-spaces. Proc Amer Math Soc. 134, 411-418 (2006)

5. Kada, O, Suzuki, T, Takahashi, W: Nonconvex minimization theorems and fixed point theorems in complete metric spaces. Math Jpn. 44, 381-391 (1996)

6. Suzuki, T: Fixed point theorems in complete metric spaces. In: Takahashi W (ed.) Nonlinear Analysis and Convex Analysis, vol. 939, pp. 173-182. RIMS, Kokyurku (1996)

7. Suzuki, T: Several fixed point theorem in complete metric spaces. Yokohama Math J. 44, 61-72 (1997)

8. Suzuki, T: Generalized distance and existence theorems in complete metric spaces. J Math Anal Appl. 253, 440-458 (2001). doi:10.1006/jmaa.2000.7151

9. Suzuki, T, Takahashi, W: Fixed point theorems and characterizations of metric completeness. Topol Methods Nonlinear Anal. 8, 371-382 (1996)

10. Saadati, R, Vaezpour, SM: Monotone generalized weak contractions in partially ordered metric spaces. Fixed Point Theory. 11(2), 375-382 (2010)

11. Shioji, N, Suzuki, T, Takahashi, W: Contractive mappings, Kannan mappings and metric completeness. Proc Am Math Soc. 126, 3117-3124 (1998). doi:10.1090/S0002-9939-98-04605-X 
12. O'Regan, D, Petrusel, A: Fixed point theorems for generalized contractions in ordered metric spaces. J Math Anal Appl. 341, 1241-1252 (2008). doi:10.1016/j.jmaa.2007.11.026

13. Agarwal, RP, El-Gebeilly, MA, O'Regan, D: Generalized contractions in partially ordered metric spaces. Appl Anal. 87, 109-116 (2008). doi:10.1080/00036810701556151

14. Wu, Y: New fixed point theorems and applications of mixed monotone operator. J Math Anal Appl. 341, 883-893 (2008). doi:10.1016/.jmaa.2007.10.063

15. Gnana Bhaskar, T, Lakshmikantham, V: Fixed point theorems in partially ordered metric spaces and applications, Nonlinear Anal. 65, 1379-1393 (2006). doi:10.1016/..na.2005.10.017

doi:10.1186/1687-1812-2011-30

Cite this article as: Graily et al:: Generalization of fixed point theorems in ordered metric spaces concerning generalized distance. Fixed Point Theory and Applications 2011 2011:30.

Submit your manuscript to a SpringerOpen ${ }^{\circ}$ journal and benefit from:

- Convenient online submission

- Rigorous peer review

- Immediate publication on acceptance

- Open access: articles freely available online

- High visibility within the field

- Retaining the copyright to your article

Submit your next manuscript at $\gg$ springeropen.com 